\title{
Peripheral Intrahepatic Cholangiocarcinoma
}

National Cancer Institute

\section{Source}

National Cancer Institute. Peripheral Intrahepatic Cholangiocarcinoma. NCI Thesaurus.

Code C96805.

An intrahepatic cholangiocarcinoma that arises from the small interlobular bile ducts. 